\title{
Calculation as a cultural practice in modern literature
}

\author{
László Bengi ${ }^{1}$ (1) \\ Published online: 25 September 2019 \\ (c) The Author(s) 2019
}

\begin{abstract}
The opposition between quantitative sciences and the humanities is a well-known problem of cultural debates, along with its reflection in the conflicting approaches to digital humanities. As the emphasis has moved from long-standing scientific methods of quantification to the overall digital turn of everyday life, this process sheds light on the varying sociocultural conditions for calculations in modern societies. Consequently, numbers cannot be conceived as inherent properties of things by discovery through experimentation and explanation: this essentialist conception seems to originate in a misunderstanding of nineteenth-century scientific research and its claim of objectivity. Rather, quantification and the cultural matrices of calculation build a raster image serving as an interface between world and mind. In this broad sense, everyday life is deeply pervaded by numbers. Moreover, the ability for calculations cannot be treated as a uniform skill any more. Instead, it varies in accordance with different cultural forms and functions. Number-based practices are also represented widely in modern literature and in non-literary works, such as being in the letters and diaries of many writers. The essay is thus intended to analyze and compare the forms of calculation in the novels and diaries of some East Central European writers — such as Kafka, Kosztolányi, Musil—who thrived in the first decades of the twentieth century. In so doing, it describes three models through which calculation as a cultural practice enters the field of literature.
\end{abstract}

Keywords Cultural practices $\cdot$ Numbers $\cdot$ Operational knowledge $\cdot$ Iteration in literature

On the cover of a recently published collection of essays on the possibilities of empirical and digital approaches to literature (Bode and Dixon 2009), two photographs are placed next to one another. The left one shows the museum-like interior of a library hall, with bright, square and evenly arranged windows on the ceiling.

\section{László Bengi}

lbengi@elte.hu

1 Department of Comparative Literature and Cultural Studies, ELTE Eötvös Loránd University, Múzeum krt. 4/A, Budapest 1088, Hungary 
The right one depicts a very similar arrangement of blackish microprocessors, supposedly part of a large digital device. Although these photographs might represent a certain kind of technological progress, their similar structure suggests that a desired harmony also accompanies the undeniable contrast between classical and digital scholarship. In the first chapter of her recent book, one of the editors, Bode (2018), argues that close and distant reading are not necessarily as far away from one another as is frequently assumed in digital humanities. Both methods of reading can be treated as highly equivalent forms of literary analysis in regard to the (sometimes naive) claim of objectivity and their ahistorical character. Thus, they reduce the heterogeneity and complexity of literary phenomena, even if in a significantly different manner. Bode instead offers an approach that synthetizes the contributions of close and distant reading with the long-standing tradition of textual scholarship, mainly as it was developed in the practices of creating scholarly editions. To analyze the synchronic and diachronic variabilities of the literary field properly, philology provides a wide (and sometimes wild) inventory of critical and historical methods of investigation.

Nevertheless, opposed to Bode's rather optimistic - but in no way naive-point of view, the increasing importance of quantification and the interpretative attitude of the humanities have been in permanent conflict throughout modernity. Snow (2012), in his famous essay on "two cultures," originally published in 1959, deliberately talked about a deep rupture between the human and the natural sciences. In Snow's argumentation, this opposition is not merely considered as a difference that comes from, and results in, a sharp methodological dualism-the idea of which dates back to Geisteswissenschaft in its Diltheyan form-but as a general inability of communication and understanding between literary intellectuals and scientists. Although Hayles (2012), similarly to Bode, argues that, under the current conditions, a certain synergy of close, hyper and machine reading is desirable, she also warns that the reaffirmation of a "rift between print-based and digital scholarship would have significant implications for both sides. Print-based scholars would become increasingly marginalized [...]. Digital humanities would become cut off from the rich resources of print traditions, leaving behind millennia of thought, expression, and practice that no longer seem relevant to its concerns" (pp. 6-7).

In the polarized situation of contemporary cultural and literary studies, it seems to be exceedingly important how the relation of quantitative properties and cultural practices is reflected in the history of modern literature. Does the reading of modernist literary works confirm a strict dichotomy between numerical operations and aesthetic experience, quantification and poetical features? I will argue that such an assumption would be a misleading oversimplification. Literature does not represent calculation in a uniform way but as being interwoven into the matrix of heterogeneous cultural discourses. Thus, the relation of numerical reasoning and literary expression, as well as being full of tension, significantly varies in accordance with the cultural function of calculation. Therefore, firstly, the essay intends to show that the effect of quantification cannot be confined to the certainty of " $2 \times 2=4$ " or to the uniformity implied by the numerical measurement and ordering of physical properties and social conditions. The narrow concept that literary studies formed about calculation should be reinterpreted so 
that it conforms a bit more to the colorful field of mathematics. In the remainder of the essay, I will outline three models through which different relations to mathematical operations are articulated in both literary and para-literary forms.

The dual tendency of modernism to both incorporate and reject the use of calculative operations in cultural practices can easily be overshadowed by concentrating exclusively on numerical transformations and statistical representations that have pervaded everyday life since at least the last decades of the nineteenth century. It is not by chance that Connor (2017), exploring the significant roles that the world of numbers plays in the arts, gave his book the subtitle "In defense of quantity." On the one hand, numericalization or quantification threatened to subordinate the expressivity of language to rigid operations; on the other hand, the subtle notational systems like literature disclosed the potential of languages to perform complex operations, including calculations (cf. Krämer 2003, p. 529). Modernism, thus, maintained a rather ambivalent relationship with calculation, since differentiating letters and numbers, expressive and operative discourses, and symbolic and formal languages could generally be as important in the modernist intellectual climate of the early twentieth century as the attempt to keep together what was tempting to separate. In the first decades of the twentieth century, calculation could be seen either as a bridge or as a gap between the everyday experience of world and the interpretative effort of reason.

At the dawn of our digital era, it would be hard to decide whether the cultural transformation brought about by computerization passes beyond the European tradition of surface-substance dichotomy to a unifying system of numerical representation, or just evokes a misleading substitution of visualizing interfaces driven by strict and uniform numerical analysis for quantified description. In light of this dilemma, however, the ambivalent view of modernism on the operative discourses of calculation might gain new interpretative relevance for present cultural practices. As the all-embracing process of digital transformation highlights how deeply everyday life is pervaded by numbers, it no longer makes sense to assume that the quantitative elaborations of understanding and the humanities form two distinct universes - either in the sciences or in everyday life. Nevertheless, literature has never ceased to maintain a skeptical, or at least reflexive, attitude toward the generalization of numerical relations. This approach puts the emphasis on the complex interaction by which calculative and non-quantitative discourses intermingle all the time, instead of supposing a homogeneous field of relations without the possibility of differentiating between cultural phenomena.

As a set of mathematical operations, or even as a wide range of everyday practices to organize one's life-world, calculation cannot be restricted to the field of numerical relations. Although in the philosophy of mathematics it is possible to argue that counting - the notion of numbers in general-is a necessary condition for calculation, it is also important to emphasize that calculations are not necessarily executed numerically. In this sense, numeration is a narrower notion than calculation that embraces a much larger scope of operations. If the focus of cultural analysis shifts from considering the functions of numbers in themselves to the various forms of discursive embeddedness of calculation, then the relation of 
modern literature to the mathematical or-more appropriately-formal construction and interpretation of the world can be seen somewhat differently.

Books on mathematical analysis or calculus regularly skip the definition of their subject in its general meaning. It is not probably independent of the acute tension "between practicality and theoretical musing: between solving problems and understanding the problem" (Juola and Ramsay 2017, p. 278), as a recent handbook on mathematics for humanists describes the ambiguous reception of the disciplinary field of "calculus." On the one hand, the authors do not hesitate to admit that "it is one of the most eminently practical systems ever created for solving a truly vast set of problems. Calculus is, in this sense, the ultimate form of applied mathematics" (p. 277). On the other hand, they "can think of very few conceptual problems involving numbers that don't eventually wend their way around to the philosophical conundrums that gave rise the invention of the calculus, and which continue to inform its theoretical basis" (p. 278). Opposed to the approach of Alain Badiou (2008) in his thorough and technical analysis of the construction of numbers (see also the critical remarks of Nirenberg and Nirenberg 2011), the third model mentioned in this essay to grasp the interplay between calculative and literary practices primarily rests and depends on the theoretical and philosophical interpretation of mathematical analysis. It does not intend to deny the mutual interdependence of number theory and calculus but to emphasize that the symbolic machinery of mathematics can also be revealed without the discussion of numerical execution.

As a consequence, the exploration of the relationship between literature and calculation as intertwining cultural discourses requires the broadening of the field of interest in four strongly related senses. First, on the thematic level, it means that even texts in which numbers or counting are not explicitly present might still be relevant. Second, beside the most pervasive model of economics (cf. Connor 2017, p. 46), other possible patterns of cultural interactions - such as the abstract field of operations - can also be taken into consideration. In this regard, a relevant counterargument comes from the fact that many writers were (and are) unable to comprehend the idea behind the abstract and highly technical elaborations of mathematical problems. This is exactly the reason why the essay will propose models that induce, motivate and govern the interaction between mathematical operations and aesthetic reception, instead of supposing the unmediated influence of higher mathematics in each case. In other words, abstract constructions are, by definition, abstract in the sense that they are not bound to one particular experience but can appear even in the most different spheres of life such as, e.g., literature. Third, on the level of interpretative strategies, as well as "number-magic" and "numerology" (Connor 2017, pp. 15-16) losing their efficiency in linking literature and calculation, with both modernizing rapidly, the ongoing tradition of number symbolism is no longer sufficient to undertake this role either. Even though it still serves several fundamental metaphorical and rhetorical functions in the modern era, number symbolism does not cover the scope of narrative and poetical problems that fall beyond the representation of strictly numerical or quantifiable constructions of literary works. Finally, the broadening of the notion of calculation rejects the reduction of cultural complexity in the sense that the role played by literature in the interaction with mathematical operations cannot be constrained to a merely defensive position. 
The first and probably most common model is based on economy and the more or less everyday experience of the market, trade, and the circulation of money. Since financial trends cannot be foreseen completely, this model notably relies on the (possible) application of statistics (the social and sociocultural context of statistical inference and probability theory is analyzed in detail by Hacking 1990; Porter 1995; Campe 2012). Simple financial calculations as well as statistical inferences are frequently articulated in series of records (regarding Defoe, cf. Campe 2012, pp. 220-234), and it makes diaries and letters the prototypical-but by no means exclusive-media of the interaction governed by the economic model. In fiction, it might become a significant pattern of composition-together with the model of measurement mentioned below-in works designed to build or explore the rules and components of a particular world as the context of the narrated story. Together with certain types of realist novels, the genres of crime fiction and sci-fi can be mentioned as examples.

In many of the journal entries and letters, the recording of several events and the-mainly intuitive-statistical-like interpretation of observations serve as a disciplinary basis for self-discipline. Although economic interpretations of one's lifeworld commonly mark a strategy for self-regulation, the modality and the discursive position of these passages vary greatly: restrictive and retrospective practice can be differentiated from the speculative, basically expansive and future-oriented way of calculations. The effect of financial conditions on an individual's way of life and even cultural habits is evident in a letter written by the young poet, Árpád Tóth, to his parents in 1906, when he and his brother studied in Budapest:

All of these have, unfortunately, cost money. [...] We have already paid the apartment rent for the period until the 15th, but for breakfasts we will have to pay 4.50-4.80 forints to our current housekeeper by the 15 th of the next month. Our financial situation is as follows: today I withdrew 20 koronas, so the balance is still 18 koronas. [...] The 20 koronas I withdrew today will be enough for about 9-10 days because we do not spend more than 1 forint a day, and we do not have dinner in expensive restaurants that cost $20+20=40$ kreutzers every evening, as instead we eat cottage cheese or something similar for dinner, and thus, in all, together with bread, our dinner costs only 20 kreutzers. [...] In addition, theatres: since March 29th, we have been to the Comic Theatre twice and the National Theatre once, which cost 40 and 50-50 kreutzers, respectively. (Tóth 1973, p. 14; translation is mine.)

The stationary, equilibrium-oriented, and substantially restrictive approach characterizing most of Tóth's letters can be contrasted with successive, progress-driven efforts. Such efforts are also expressed in the diaries of Zsigmond Móricz, one of the greatest novelists of the interwar period in Hungary. The following entry is from 1932:

It will cost 2000 koronas to dig out the well, so I have to run into debt for it, and what is more, I have to do so hastily. But my colleagues at the journal Nyugat help me in many ways [...]. The water conduit would cost 3000 pengos, while in this way, hardly 2000, I hope. And by this, I gain perpetual value 
since the garden, if there is water in it, can make some profit. Now, I have a good gardener who is an aging, hard-working and trustworthy man, or so it appears, and he has already minimized the expenses for the garden. [...] Without water, he won't be able to raise anything, but if there will be water, then it will be possible to do so. Speculation it is, but I think it is good speculation, and it is the reason why I adhere so much to this idea. (Móricz 2016, p. 129; translation is mine.)

As a physician and psychiatrist, Géza Csáth-beside the permanent calculation of his financial status - kept a detailed quantitative record of his own physical conditions. In line with contemporaneous psychology, he applied a clear economic model to personality by explaining behavior as an interaction of different complexes of drives. Therefore, in the 1910s, he gave long and precise enumerations about his health, especially about the exact weight of drugs - mainly the morphine he took day by day - as well as about the sexual intercourses he had with his wife and with other ladies, some of his patients (Csáth's diaries are among the cruelest readings in Hungarian literature). His records mostly shatter the narrative frame, and include cumulative tables and simple enumerations of data (e.g., Csáth 2017, pp. 257, 325, 375-376). The entries form an unsettled sequence of alternating periods in which, on the one hand, Csáth tried to sustain an equilibrium of taking drugs, doing work, etc., and through which, on the other hand, he was optimistic of progressing in his episodic efforts to give up drugs.

A similarly ambivalent experience evolves in Kafka's diaries. This ambiguity, however, does not stem from the dialectical personal drives to reach a steady-state equilibrium and to increase prosperity in life but from a self-contradictory attitude toward the economic model in general. As is frequently the case with non-literary works of the early twentieth century, more common forms of counting come to the fore in Kafka's numerous letters and diaries. Several times he stresses the irreconcilable opposition between the office (or the factory) characterized by the permanent demand for statistics, accounts, and reports, and literary writing. Kafka complains about his unusual daily routine and, as a good official, relentlessly calculates the possibilities for minimizing the lost time he could have spent writing. In his letters, he urges his sweetheart to write more regularly, compiles reports of how many letters he received and how many he did not get. Later, as a fiancé, he weighs the gains and losses of the anticipated marriage for both participants. In this respect, Kafka's relation to numerical calculation is not ambivalent, but is clearly paradoxical. He keeps counting the conditions for getting rid of numeration.

In relation to calculation as a cultural practice, physical explanation also serves as an influential model of literary discourse. It relies on the design of measurements, instead of statistical data analysis. Although Thomas Kuhn, within the history of physical sciences, differentiated between observation and measurement on the basis that the latter "always produces actual numbers" (Kuhn 1961, p. 162), in modern literature, this difference seems to be of secondary importance. While the possibility of numericalization is a necessary requirement, literature does not intend measurements to be carried out. For instance, the characters of Robert Musil and Dezső Kosztolányi in the novels mentioned below are not really fond of numerical 
problems but of the conceptual relation of calculation and everyday life. Hence, the peculiar medium in which measurements appear as a meaningful cultural model of calculation is the structure of narrative motifs. Moreover, as a metaphoric field of interacting textual elements, this model frequently reflects on the pattern of communication between characters and thus highlights the social conditions of identity formation. In fact, the symbolic interpretation of numbers like zero and one or the notions of manifold and infinity can be developed within the model based on the physical explanation of interacting forces.

The sensitive and smart protagonist of The Confusions of Young Törless, a novel published in 1906 by Musil, becomes highly excited over getting acquainted with complex numbers. Although Törless seems to be enthusiastic, his doubts are no less important:

what is actually so odd is that you can really go through quite ordinary operations with imaginary or other impossible quantities, all the same, and come out at the end with a tangible result! [...] in a calculation like that you begin with ordinary solid numbers, representing measures of length or weight or something else that's quite tangible - at any rate, they're real numbers. And at the end you have real numbers. But these two lots of real numbers are connected by something that simply doesn't exist. Isn't that like a bridge where the piles are there only at the beginning and at the end, with none in the middle, and yet one crosses it just as surely and safely as if the whole of it were there? That sort of operation makes me feel a bit giddy, as if it led part of the way God knows where. But what I really feel is so uncanny is the force that lies in a problem like that, which keeps such a firm hold on you that in the end you land safely on the other side. (Musil 1955, pp. 106-107)

According to Törless, imaginary numbers suspend or at least disrupt counting with real-more or less referential-numbers (Dipert 2003, pp. 151-152). Since the unreality of the imaginary unit, the acting of an operator where it should not operate, blurs the established rules of ordinary mathematics, complex numbers cannot be treated as tools for grasping the essence of physical phenomena. In other words, the imaginary unit is supposed to be a gap in reasoning and also a bridge between different parcels of reality, but not the (hidden) depth below this bridge. It could be the possible source of Törless' doubts. Moreover, the difference between gap and depth also echoes the epigraph from "Mystic Morality," an essay by Maurice Maeterlinck, which allegorically opposes the "uttermost depth" and the "surface," the "darkness" of the "abyss" and "the light of day."

How strangely do we diminish a thing as soon as we try to express it in words! We believe we have dived down to the most unfathomable depths, and when we reappear on the surface, the drop of water that glistens on our trembling finger-tips no longer resembles the sea from which it came. We believe we have discovered a grotto that is stored with bewildering treasure; we come back to the light of day, and the gems we have brought are false-mere pieces of glass - and yet does the treasure shine on, unceasingly, in the darkness! (Maeterlinck 1905, p. 34) 
While the symbolic connotations of the epigraph express linguistic skepticism, Young Törless finds a possible answer to the surface-substance opposition through the intellectual challenge of performing calculations with imaginary numbers. Finally, the experience of Törless is also important regarding the relation of lesson and life-i.e., the theoretical comprehension of mathematical operations and the pragmatic effort to understand and organize the world: "For some days past he [Törless] had been following lessons with special interest, thinking to himself: 'If this is really supposed to be preparation for life, as they say, it must surely contain some clue to what I am looking for, too.' It was actually of mathematics that he had been thinking [...]" (Musil 1955, p. 104). In this way, Musil's protagonist develops not only an ambivalent relation to non-elementary calculation, but also a pattern in which the discourses of mathematics, literary symbolism, and everyday experience are interwoven. A main character-although not the protagonist-of a Hungarian novel published about 20 years later, The Golden Kite by Kosztolányi, has a different relation to calculation. Vilmos Liszner is also a high-school student. Preparing for the legendarily tough graduation exams, and different from Young Törless, he is much more motivated to reach outstanding results in sports than in sciences:

[Liszner] was reluctantly thumbing the mathematics workbook, with slow and dumb attention.

He was able to read it for hours. Someone has bought five meters of baize... 8 years ago, the father was exactly one hundred times older than his son... a rich man has hired two farm servants... He was wandering about all these situations. The facts, the persons, the objects were entertaining him, and it even did not come into his mind that the exercises could be, or should be, solved. He persisted in warping his lazy dreams. He was wandering what color that baize is? And who is that father and that certain son? Does the old boy have a beard and can his son cycle? Then where must that rich guy have lived? But whenever it came to counting, he immediately lost his amusement and brushed aside the whole thing by insisting that he does not need any baize, and the father, the son and the rich man are all boring and witless idiots. (Kosztolányi 2014, p. 159; translation is mine.)

Liszner does not treat abstract mathematical manipulation as an extension of reality that can be usefully integrated into the interpretation of the world; rather, he separates numerical operations from everyday phenomena. Thus, his rejection of calculation reaffirms the effects of quantification instead of adequately answering to this challenge. This unsuccessful situation is also reflected in the story: Liszner is a narrow-minded student who, after failing the graduation exam, even beats his highschool professor of physics and mathematics, Antal Novák.

Professor Novák is seemingly the opposite of Liszner. While he handles scientific problems self-confidently, he is unable to tolerate emotions becoming a more important motivation for human behavior than pure reason. Committing suicide, he becomes a tragic hero, but the fact that he can hardly understand other people, including his own daughter, makes him a comic figure too. Ironically, both Novák and Liszner, just from opposite sides, suffer from the cognitive dissonance that comes from the detachment of actual physical phenomena from abstract ideas. No 
character in the novel is able to find a harmonic relation of the different measures attached to different discourses. In this situation, the characters are also unable to communicate with each other or express their desires, fears, compassion, and empathy. By lacking solutions, The Golden Kite shows the problems that rise from the unmediated opposition between the organizing power of calculation and the irrational realms of instinctual motives.

The last model I mention in this essay is based on philosophical reasoning. Having adapted mathematical relations along this model, the strictly numerical operations are transformed as logical inferences or mental operations. Since these are rather procedural features, they are in close relation to the poetic functions of literary discourse-i.e., to the textual strategies by which the story as a chain of events and the fictive world unfolds in the act of reading. The representation of operations, including cognitive modeling of the world, necessarily involves self-understanding and thus sheds light on the reflective character of modern subjectivity. In this respect, this is the most abstract model for the interplay between calculation and literature, since numbers are overshadowed here by the machinery of abstract transformations. It is organized around operators that, by projecting fields onto one another, are able to constitute mathematical structures or, so to speak, correspondences between different worlds.

The novels by Musil and Kosztolányi as well as many of the diary entries by Kafka embedded calculation in different discursive contexts, showing the ambivalence evoked by both the integration and rejection of abstract mathematical operations. It is, however, only one layer of Kafka's rich writing. Deleuze and Guattari (1986) have already called attention to the extensive presence of series in Kafka's works. In 1916, Kafka wrote to himself:

Mend your ways, escape officialdom, start seeing what you are instead of calculating what you should become. [...] As a link in the chain of calculation, they [Flaubert, Kierkegaard, and Grillparzer] undoubtedly serve as useful examples-or rather useless examples, for they are part of the whole useless chain of calculation; all by themselves, however, the comparisons are useless right off. Flaubert and Kierkegaard knew very clearly how matters stood with them, were man of decision, did not calculate but acted. But in your casea perpetual succession of calculation, a monstrous four years' up and down. (Kafka 1949, pp. 164-165)

Since there are more than two parts, it is not possible to arrange them in simple opposition, but their chain forms a sequence or a series. A biographical reason exists for this, inasmuch as Kafka was a German-speaking person of Jewish origin who lived in Prague, which belonged to the Austro-Hungarian Monarchy at that time. However, the iterative chain of transformations is also articulated as a textual experience in Kafka's literary works. The operation performed to produce sequences appears in narrative forms, in short stories like "Poseidon," "Fellowship," and "An Imperial Message." The latter contains the following passage:

[The messenger] is only making his way through the chambers of the innermost palace; never will he get to the end of them; and if he succeeded in that 
nothing would be gained; he must next fight his way down the stair; and if he succeeded in that nothing would be gained; the courts would still have to be crossed; and after the courts the second outer palace; and once more stairs and courts; and once more another palace; and so on for thousands of years; and if at last he should burst through the outermost gate-but never, never can that happen-the imperial capital would lie before him, the center of the world, crammed to bursting with its own sediment. (Kafka 1971, p. 5)

In the mathematical sense, they raise the question of the limit of an infinite series and, to some extent, allude to Zeno's paradoxes reformulated as parable in "The Next Village." According to Zeno, Achilles cannot reach the tortoise since their motion can be broken down into an infinite number of fragments, and in all of them, Achilles' distance from the tortoise is not zero. Nevertheless, it might be a misleading parallelism because - as is shown in mathematical analysis - the constructed series of distances converges to a finite limit, despite the infinite number of elements to be summed. It seems to be more consistent with the operation of successive approximation in Kafka's narratives if it is described as the result of a recursive process (Corngold 2002, pp. 104-105; Beebee 2012, p. 94). Beebee nested this approach, inspired by Luhmann's system theory, into the analysis of law and bureaucracy in The Trial. To put it in a very simple way, the application of law requires the legal regulation of the process by which specific legal rules can be employed under different circumstances. In other words, rhetorical pattern, mathematical operation and legal system are joined in a somewhat fearful algorithm. This resonating structure reveals that, by the beginning of the twentieth century, slightly after the transformation of modern mathematics, it had become a general cultural practice.

Kafka stands in a threefold and deeply ambivalent relationship to calculation. First, he curses time-consuming numerical tasks of administration. Meanwhile, he permanently looks for an optimal timetable for writing, seemingly without calculation. Finally, he widely applies a sequential form of calculation as a rhetorical pattern in his narrative works. Modernist writers did not set aside critical remarks on counting and numerical reporting, yet their writings are substantially pervaded by mathematical operations, suggesting that calculation was never really a mere scientific project of quantification. Opposed to the artificial separation of discourses, this tradition of critical integration can still motivate reflection on calculation as something that inseparably belongs to, but is not equal to, us.

In this essay, I argued in favor of broadening the question of the relationship between calculation and literature beyond the function of numbers in literary work. Calculation is not a uniform practice of simple numerical operations but a diverse field of discourses with different axiological implications and cultural functions. There are several models through which calculation enters literature. Out of these numerous possibilities, the models based on economic equilibrium, physical explanation, and philosophical inference were analyzed here. These three modelsalthough not completely separable-differ from each other in several respects. They rely upon different facets of calculation as a multimodal cultural practice: statistics (and probability), measurement (and quantifiable observation), and operations (and cognitive processes). They are most properly expressed by different generic or 
textual features-i.e., by the enumerative records of events, the integrative structure of motifs, or the narrative iteration of operations. Finally, all of these models play a specific role in determining the position and structure of modern subjectivity: (self-) regulation oscillates between equilibrium and progress, (self-)expression evokes the scope of personal interaction and the level of psychological consistency, and (self-) reflection induces increased awareness and processual identification of the subject. At this point, two conclusions have to be drawn.

First, since the models are strictly interconnected and their characteristics cannot be defined exclusively, the features mentioned above mark only differences in emphasis, and form a matrix with highly correlated elements. Second, as the advocates of the empirical research of digital humanities suggest a complex interaction between traditional and newborn forms of reading, the pervasive experience of calculation in modern literature also constitutes an intriguing synergy of cultural practices, thus also providing a critical view on the techniques of quantification.

Acknowledgements Open access funding provided by Eötvös Loránd University (ELTE). This paper was supported by the János Bolyai Research Scholarship of the Hungarian Academy of Sciences.

Open Access This article is distributed under the terms of the Creative Commons Attribution 4.0 International License (http://creativecommons.org/licenses/by/4.0/), which permits unrestricted use, distribution, and reproduction in any medium, provided you give appropriate credit to the original author(s) and the source, provide a link to the Creative Commons license, and indicate if changes were made.

\section{References}

Badiou, A. (2008). Number and numbers (R. Mackay, Trans.). Cambridge: Polity Press.

Beebee, T. O. (2012). Citation and precedent: Conjunctions and disjunctions of German law and literature. New York and London: Continuum.

Bode, K. (2018). A world of fiction: Digital collections and the future of literary history. Ann Arbor: University of Michigan Press.

Bode, K., \& Dixon, R. (Eds.). (2009). Resourceful reading: The new empiricism, eResearch, and Australian literary culture. Sydney: Sydney University Press.

Campe, R. (2012). The game of probability: Literature and calculation from Pascal to Kleist (E. H. Wiggins, Jr., Trans.). Stanford: Stanford University Press.

Connor, S. (2017). Living by numbers: In defence of quantity. London: Reaktion Books.

Corngold, S. (2002). Kafka's later stories and aphorisms. In J. Preece (Ed.), The Cambridge companion to Kafka (pp. 95-110). Cambridge: Cambridge University Press.

Csáth, G. (2017). Sötét örvénybe süllyedek: Naplófeljegyzések és visszaemlékezések 1914-1919 [I sink into a deep maelstrom: Diaries and memoires 1914-1919]. Ed. E. E. Molnár, and M. Szajbély. Budapest: Magvető.

Deleuze, G., \& Guattari, F. (1986). Kafka: Toward a minor literature (D. Polan, Trans.). Minneapolis and London: University of Minnesota Press.

Dipert, R. R. (2003). Mathematics in Musil. In W. Huemer \& M.-O. Schuster (Eds.), Writing the Austrian traditions: Relations between philosophy and literature (pp. 143-159). Edmonton: Wirth-Institute for Austrian and Central European Studies.

Hacking, I. (1990). The taming of chance. Cambridge: Cambridge University Press.

Hayles, N. K. (2012). How we think: Digital media and contemporary technogenesis. Chicago and London: The University of Chicago Press.

Juola, P., \& Ramsay, S. (2017). Six Septembers: Mathematics for the humanist. Lincoln: Zea Books. 
Kafka, F. (1949). Diaries (M. Brod, Ed., M. Greenberg \& H. Arendt, Trans.). New York: Schocken Books.

Kafka, F. (1971). An imperial message. In The complete stories (W. Muir \& E. Muir, Trans.) (pp. 4-5). New York: Schocken Books.

Kosztolányi, D. (2014). Aranysárkány [The golden kite]. Pozsony: Kalligram.

Krämer, S. (2003). Writing, notational iconicity, calculus: On writing as a cultural technique. $M L N, 118$, 518-537.

Kuhn, T. S. (1961). The function of measurement in modern physical science. Isis, 52, 161-193.

Maeterlinck, M. (1905). Mystic morality. In The treasure of the humble (A. Sutro, Trans.) (pp. 59-74). London: George Allen.

Móricz, Z. (2016). Naplók: 1930-1934 [Diaries] (Ed., A. Cséve \& J. Z. Szilágyi). Budapest: Noran.

Musil, R. (1955). Young Törless (E. Wilkins \& E. Kaiser, Trans.). New York: Pantheon.

Nirenberg, R. L., \& Nirenberg, D. (2011). Badiou's number: A critique of mathematics as ontology. Critical Inquiry, 37, 583-614.

Porter, T. M. (1995). Trust in numbers: The pursuit of objectivity in science and public life. Princeton: Princeton University Press.

Snow, C. P. (2012). The two cultures. An introduction by Stefan Collini. Cambridge: Cambridge University Press.

Tóth, Á. (1973). Levelei [Letters] (Ed., L. Kardos, P. Kardos \& G. Kocztur). Budapest: Akadémiai.

Publisher's Note Springer Nature remains neutral with regard to jurisdictional claims in published maps and institutional affiliations. 